\title{
Nordic Snow Radar Experiment
}

\author{
Juha Lemmetyinen ${ }^{1}$, Anna Kontu ${ }^{1}$, Jouni Pulliainen ${ }^{1}$, Juho Vehviläinen ${ }^{1}$, Kimmo Rautiainen ${ }^{1}$, Andreas Wiesmann ${ }^{2}$, \\ Christian Mätzler ${ }^{2}$, Charles Werner $^{2}$, Helmut Rott $^{3,4}$, Thomas Nagler ${ }^{3}$, Martin Schneebeli ${ }^{5}$, Martin Proksch ${ }^{5}$, \\ Dirk Schüttemeyer $^{6}$, Michael Kern ${ }^{6}$, and Malcolm W. J. Davidson ${ }^{6}$ \\ ${ }^{1}$ Finnish Meteorological Institute, Helsinki, Finland \\ ${ }^{2}$ Gamma Remote Sensing AG, Gümlingen, Switzerland \\ ${ }^{3}$ ENVEO IT GmbH, Austria \\ ${ }^{4}$ Institute of Atmospheric and Cryospheric Sciences, University of Innsbruck, Innsbruck, Austria \\ ${ }^{5}$ WSL Institute for Snow and Avalanche Research, Davos Dorf, Switzerland \\ ${ }^{6}$ European Space Research and Technology Center, Noordwijk, the Netherlands
}

Correspondence to: Juha Lemmetyinen (juha.lemmetyinen@fmi.fi)

Received: 2 December 2015 - Published in Geosci. Instrum. Method. Data Syst. Discuss.: 4 March 2016

Revised: 30 June 2016 - Accepted: 7 July 2016 - Published: 7 September 2016

\begin{abstract}
The objective of the Nordic Snow Radar Experiment (NoSREx) campaign was to provide a continuous time series of active and passive microwave observations of snow cover at a representative location of the Arctic boreal forest area, covering a whole winter season. The activity was a part of Phase A studies for the ESA Earth Explorer 7 candidate mission CoReH2O (Cold Regions Hydrology Highresolution Observatory).

The NoSREx campaign, conducted at the Finnish Meteorological Institute Arctic Research Centre (FMI-ARC) in Sodankylä, Finland, hosted a frequency scanning scatterometer operating at frequencies from $\mathrm{X}$ - to Ku-band. The radar observations were complemented by a microwave dualpolarization radiometer system operating from $\mathrm{X}$ - to $\mathrm{W}$ bands. In situ measurements consisted of manual snow pit measurements at the main test site as well as extensive automated measurements on snow, ground and meteorological parameters.

This study provides a summary of the obtained data, detailing measurement protocols for each microwave instrument and in situ reference data. A first analysis of the microwave signatures against snow parameters is given, also comparing observed radar backscattering and microwave emission to predictions of an active/passive forward model.

All data, including the raw data observations, are available for research purposes through the European Space Agency and the Finnish Meteorological Institute. A consolidated dataset of observations, comprising the key microwave and
\end{abstract}

in situ observations, is provided through the ESA campaign data portal to enable easy access to the data.

\section{Introduction}

Knowledge on the duration, extent and total mass of seasonal snow cover is crucial for hydrological forecasts, numerical weather prediction and estimation of the energy balance of the Earth (Groisman et al., 1994; Brasnett, 1999; Barnett et al., 2005). Seasonal snow cover is also a strong indicator of global climate change (Derksen and Brown, 2012). The scarcity of observation networks makes data collected in situ unreliable for Arctic and boreal areas, making Earth observation from satellites an appealing option. The extent of seasonal snow cover can be retrieved with high spatial accuracy using both optical and radar sensors. Satellite-based methods for retrieving snow mass, or snow water equivalent (SWE), presently rely on passive microwave sensors (Kelly et al., 2003; Takala et al., 2011). Although these provide good global coverage and a long history of observations, present products suffer in terms of accuracy from the inherent coarse spatial resolution of passive microwave sensors over inhomogeneous areas.

Providing high-resolution information on the mass of seasonal snow cover was the main objective of $\mathrm{CoReH} 2 \mathrm{O}$ (Cold Regions Hydrology High-Resolution Observatory), a candidate mission for the European Space Agency's Earth Ex- 
plorer 7 (ESA, 2012). The payload of $\mathrm{CoReH} 2 \mathrm{O}$ was envisaged as a dual-polarized, dual-frequency (X-and Ku-band) synthetic aperture radar (SAR), with the capability of detecting SWE, as well as snow accumulation on glaciers, at spatial resolutions ranging from 200 to $500 \mathrm{~m}$ (Rott et al., 2012). In order to support the development of geophysical retrieval algorithms for CoReH2O, the NoSREx (Nordic Snow Radar Experiment) was initiated by ESA in 2009. The aim of the campaign was to collect near-continuous observations of snow cover radar signatures in the boreal forest/taiga region using a tower-based configuration, supported by frequent in situ observations. The campaign was designed to cover entire winter periods from snow-free conditions to eventual snow melt-off. With several extensions, the collected dataset for NoSREx covers a total of four snow seasons from 2009 to 2013, referred to as NoSREx I to IV in this article. The campaign was conducted at the Finnish Meteorological Institute Arctic Research Centre (FMI-ARC) in Sodankylä, Finland. The radar backscatter measurements were complemented by multi-frequency microwave radiometer observations and numerous in situ observations of snow, soil and atmospheric properties, using both manual and automated methods. Advanced methods for quantifying the snow microstructure were implemented on a campaign basis. The campaign provides a unique, near-continuous dataset of coinciding active and passive microwave observations of snow cover and diverse measurements of snow characteristics.

Data collected during NoSREx have found use in numerous recent studies exploring the modelling of microwave signatures of snow-covered terrain (Proksch et al., 2015b; Tan et al., 2015; Chang et al., 2015; Pan et al., 2016). Here, we provide an overview of the instrumentation and data acquisition protocols used and of the collected microwave signatures. The calibration accuracy of the various instruments is discussed. We also give recommendations and suggestions on how in situ data could be used optimally to support analysis of microwave observations. We discuss recent studies which have already exploited the results of the campaign and give recommendations for future experimental campaigns on snow microwave signatures.

\section{Description of experiment setup}

\subsection{Measurement location}

The main test site of NoSREx, the intensive observation area (IOA; $\left.67.3618^{\circ} \mathrm{N}, 26.6338^{\circ} \mathrm{E}\right)$, was located on a forest clearing surrounded by a sparse spruce/pine-dominated forest. The site, as well as the area at large, represents a typical boreal forest/taiga landscape. According to composition survey, the soil at the IOA consisted of sand (70\%), and clay $(1 \%)$ with a thin organic surface-layer $(2-5 \mathrm{~cm})$. The sparse ground vegetation consisted mainly of lichen, heather and other small vegetation typical for the boreal forest region.
Small trees and bushes estimated to influence e.g. snow accumulation were manually removed from the site in autumn before the onset of snow cover.

The main microwave instruments installed were the SnowScat scatterometer (Werner et al., 2010) and the SodRad multi-frequency radiometer system. Data from an L-band instrument (Schwank et al., 2010) are available from the same site; these data are not presented here in detail as the relevant information can be found in the literature (Rautiainen et al., 2014; Lemmetyinen et al., 2016). All instruments were mounted on tower structures overlooking the forest clearing, partially allowing the same sectors of the test field to be covered, albeit at differing effective incidence angles. Automated sensors were located adjacent to the test field, as was the main location for manual snow measurements. The location of the microwave instrumentation and the approximate locations of various in situ sensors are depicted in Fig. 1. The measurement protocols for each instrument are described in detail in the following sections.

\subsection{Microwave scatterometry}

The SnowScat scatterometer, manufactured by GAMMA Remote Sensing, is a frequency step four-polarization scatterometer (vertical-vertical, horizontal-horizontal, verticalhorizontal and horizontal-vertical; VV, HH, VH and HV, respectively), operating within the frequency range of 9.2 and 17.9 GHz (Werner et al., 2010). Equipped with a positioner device, the system allows scanning in both azimuth and elevation. For NoSREx, the instrument was installed on a tower structure at the height of $9.6 \mathrm{~m}$ above ground overlooking the IOA. The instrument was set to measure regular scans of the test field, first every $3 \mathrm{~h}$ in 2009 during NoSREx I. The scan of the main measurement sector (sector 1) comprised of 17 independent look directions in azimuth at four incidence angles at $30,40,50$ and $60^{\circ}$. From the autumn of 2010 (NoSREx II), the scan interval was increased to $4 \mathrm{~h}$ to allow for scanning over an additional sector (sector 2) adjacent to the main observation section (see Fig. 1). The data presented in this study consist of calibrated sigma nought values, averaged over the full azimuth scan of sector 1. Sector 2 data, however, are included in the NoSREx consolidated datasets. The technical specifications of SnowScat are given in Table 1.

SnowScat provided an internal calibration loop for compensation of internal temperature changes. The calibration consistency was verified by measuring dedicated calibration targets before and after each scan. A $\sim 25 \mathrm{~cm}$ diameter aluminium sphere was used for all seasons, and for NoSREx III and IV an additional flat plate target of $10 \times 5 \mathrm{~cm}$ was installed.

The measurement protocol of SnowScat included two measurements of the sphere target for reference purposes. In addition, the metal plate was measured for additional refer- 


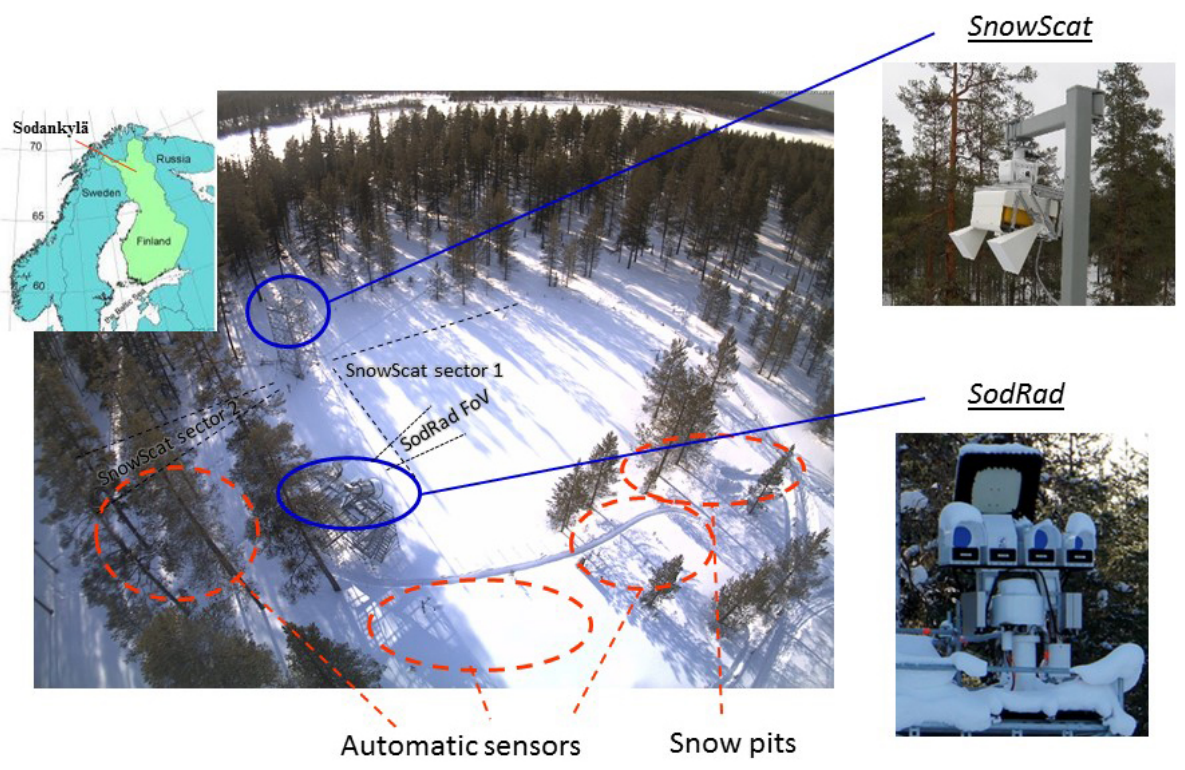

Figure 1. Webcam image of NoSREx IOA and photographs of main microwave instruments, the SnowScat scatterometer and the SodRad radiometer system.

Table 1. SnowScat technical specifications.

\begin{tabular}{ll}
\hline Parameter & Value \\
\hline Manufacturer & GAMMA Remote Sensing AG \\
Power & $230 \mathrm{~V}$, max $\sim 60 \mathrm{~W}$ \\
Weight & $\sim 40 \mathrm{~kg}$ \\
Temperature range & $-40-40^{\circ} \mathrm{C}$ \\
Antenna & Dual pol, $<10^{\circ}(3 \mathrm{~dB})$ \\
Antenna cross-pol iso & $<-20 \mathrm{~dB}$ \\
Frequency & Stepped CW from 9.15 to $17.9 \mathrm{GHz}$ \\
Incidence angle & $-40-110^{\circ}$ \\
Azimuth angle & $-180-180^{\circ}$ \\
Polarization & $\mathrm{HH}, \mathrm{HV}, \mathrm{VV}, \mathrm{VH}$ \\
Dynamic range & Receiver dynamic range $>80 \mathrm{~dB}$ \\
& with 16 bit ADC \\
Signal bias & $<0.5 \mathrm{~dB}$ \\
\hline
\end{tabular}

ence during NoSREx III and IV. The nominal scan sequence was

- sphere measurement,

- plate measurement (for NoSREx III and IV),

- sector 1 scan,

- sphere measurement,

- plate measurement (for NoSREx III and IV),

- sector 2 scan (for NoSREx II to IV).

A typical seasonal variability of co-polarized backscatter from the calibration sphere was measured to be less than $\pm 1 \mathrm{~dB}$. Larger deviations were occasionally observed but could be attributed to e.g. accumulation of snow on the sphere target.

For NoSREx III, the scan of the reference sphere was misaligned until 20 January 2012, due to human error, and calibration stability could not be verified. Measurements of the plate target in the early season proved inconclusive, as the plate target was highly susceptible to alignment errors. Therefore, SnowScat data are provided for NoSREx III only after 20 January.

\subsection{Microwave radiometry}

The SodRad system - including measurements at 10.65, $18.7,21,37$ and $90 \mathrm{GHz}(\mathrm{H}$ and $\mathrm{V}$ pol) - was mounted on a $4.1 \mathrm{~m}$ high platform overlooking the forest clearing. The $90 \mathrm{GHz}$ radiometer was available from 2009 until 2012, when it was replaced by the $21 \mathrm{GHz}$ system. Measurements were made by performing a scan in the elevation direction, resulting in ground incidence angles from 30 to $70^{\circ}$ off nadir, in steps of $5^{\circ}$. Although the system allowed scans in azimuth, most measurements were made in a single azimuth direction. In order to avoid radio frequency interference (RFI) contamination in particular at the 10.65 and $18.7 \mathrm{GHz}$ systems, the measurements were timed to occur between scans of the SnowScat instrument. Thus, the elevation scan was performed every $3 \mathrm{~h}$ during 2009-2010 and every $4 \mathrm{~h}$ in subsequent winters. In between elevation scans, SodRad was set to measure a fixed incidence angle (50 or $53^{\circ}$, depending on season). These data are available upon a separate request. The technical specifications of SodRad are given in Table 2.

The measurement sequence of SodRad consisted of 
- the elevation scan,

- a measurement of the sky cold target reference at zenith (measurement duration $10 \mathrm{~min}$ with $1 \mathrm{~s}$ integration time),

- a fixed angle measurement (until next elevation scan).

The tower-based radiometers were calibrated using a twopoint calibration with external targets, using a microwave absorber at ambient temperature and using a similar target cooled by liquid nitrogen. For NoSREx I, the stability of the radiometers was verified by measuring the sky at an elevation angle of $30^{\circ}$ from horizontal. This was done to minimize the risk of snow accumulation on antenna apertures during the sky measurement. From NoSREx II onwards, verification of radiometer stability was performed using the cold sky reference at zenith (imposing a minimal influence from changing atmospheric conditions) after each elevation scan; any accumulated snow was manually removed. During NoSREx III, sky reference measurements were conducted only in March due to problems with the instrument positioner. Additional calibration experiments included measurements of external targets before and after the campaign season, including absorber material cooled by liquid nitrogen. Calibration accuracy immediately after calibration was estimated to be better than $1 \mathrm{~K}$ for the $18.7,21,36.5$ and $90 \mathrm{GHz}$ channels and better than $2 \mathrm{~K}$ for the $10.65 \mathrm{GHz}$ channels. The increased uncertainty of the $10.65 \mathrm{GHz}$ channels is partly due to use of a large parabolic reflector in front of the antenna feed, whereas 18.7 and $36.5 \mathrm{GHz}$ channels utilize integrated horn antennas; the parabolic reflector exhibited some sidelobe effects which could not be entirely removed in the calibration. Analysis of the external calibration target experiments as well as cold sky measurements in clear-sky conditions typically indicated a drift of less than $2 \mathrm{~K}$ for all channels and polarizations during the cold winter period (December-March). The absolute values of the sky at nadir in clear-sky conditions were typically on the order of 5, 12, 18, 20 and $35 \mathrm{~K}$ for $10.65,18.7$, 21 and $36 \mathrm{GHz}$, respectively. A total of 775, 654 and 412 sky reference measurements were made during NoSREx I, II and IV, respectively. The trend during NoSREx III could not be fully analysed due to availability of sky reference data only for March (85 measurements). Moreover, during NoSREx I, the 37 and $90 \mathrm{GHz}$ channels exhibited decreasing drifts of -4 and $-9 \mathrm{~K}$, respectively, in the measured cold sky brightness temperature. The high observed drift compared to following seasons may be attributed to measuring the sky at $30^{\circ}$ elevation from horizontal for NoSREx I (in place of $90^{\circ}$ ), which emphasizes variability in the prevailing weather conditions (e.g. atmospheric water vapour) due to the larger air mass in the signal path.

\subsection{Manual in situ data collection}

Manual snow observations consisted of weekly snow pit measurements. Snow pits were made at a distance of ca. 10-
Table 2. SodRad technical specifications.

\begin{tabular}{ll}
\hline Parameter & Value \\
\hline Manufacturer & Radiometer Physics GmbH \\
Power & $\sim 300 \mathrm{~W}$ average, $500 \mathrm{~W}$ peak \\
Weight & $405 \mathrm{~kg}$ (including positioner) \\
Temperature range & $-40-45^{\circ} \mathrm{C}$ \\
Receiver \& antenna & $<0.05 \mathrm{~K}$ \\
thermal stabilization & \\
Antenna $\theta_{3} \mathrm{~dB}$ & $<6.1^{\circ}$ \\
Antenna sidelobe level & $<-30 \mathrm{dBc}$ \\
Incidence angle & $30^{\circ}<\theta<330^{\circ}$ \\
Azimuth angle & $360^{\circ}$ \\
Polarization & $\mathrm{V}$ and $\mathrm{H}$ \\
Frequencies & $10.65,18.7,21,36.5,90 \mathrm{GHz}$ \\
Bandwidth & $400 \mathrm{MHz}$ \\
System noise temperatures & $<900 \mathrm{~K}$ \\
Dynamic range & $0-350 \mathrm{~K}$ \\
System stability & $1.0 \mathrm{~K}$ \\
Radiometric resolution & $0.2 \mathrm{~K} \mathrm{RMSE} \mathrm{@} \mathrm{1} \mathrm{s} \mathrm{integration} \mathrm{time}$ \\
\hline
\end{tabular}

$20 \mathrm{~m}$ from the radiometer footprints in the same measurement field (Fig. 1). Due to the destructive nature of snow pit measurements, consecutive pits were made at a distance of $50-100 \mathrm{~cm}$ from the previous pit. Measured parameters included bulk snow depth (SD), density and SWE using a snow corer and manual scale, snow density profiles at $5 \mathrm{~cm}$ intervals using a $250 \mathrm{~cm}^{3}$ manual cutter and scale, snow temperature profile at $10 \mathrm{~cm}$ intervals using a digital thermometer, an assessment of snow layering based on a manual assessment of snow hardness variations, and snow grain size and type estimation. The snow grain size and type were estimated visually from macro-photography of snow samples, taken against a $1 \mathrm{~mm}$ reference grid. A grain size classification was made following Fierz et al. (2009); in addition, the typical grain size (average maximum diameter of typical snow grains, referred to hereafter as $E$ ) was estimated visually. One snow sample was taken from the centre of each identified snow layer, and the estimated grain size of the sample was considered to be applicable for the whole layer.

During NoSREx III and IV, snow specific surface area (SSA) was measured with the IceCube instrument manufactured by A2 Photonic Sensors, France. The measurement is based on IR reflectance of a snow sample placed inside an integrating sphere (Gallet et al., 2009). The vertical snow profile was sampled at $3 \mathrm{~cm}$ resolution, excluding hard-packed layers which presented difficulties for sampling. The time series of SSA measurements are not a part of the NoSREx consolidated datasets but are available on separate request. A detailed description of the manual snow observation programme, of which the snow pit measurements are a part, is given by Leppänen et al. (2016).

As snow pit observations were not made directly in the footprint of microwave instruments, with the exception of 
Table 3. Automated data collected in NoSREx consolidated datasets from Sodankylä mini automated weather station (MAWS), the IOA automated weather station and the IOA Gamma Water Instrument.

\begin{tabular}{lll}
\hline Sensor array & Variable & Instrument \\
\hline & Average $2 \mathrm{~m}$ air temperature & Pentronic PT100 \\
& Average dew point temperature & Pentronic PT100 \\
& Average wind speed & Vaisala WAA25 \\
& Maximum wind gust & Vaisala WAA25 \\
& Average pressure reduced to sea level & Vaisala PTB201A \\
AWS & Average pressure at station level & Vaisala PTB201A \\
& Mode of present weather ww-code/synop & - \\
& Average height of the lowest clouds & Vaisala CT25K \\
& Mode of height of the lowest clouds & Vaisala CT25K \\
& Average of total cloudiness & Vaisala CT25K \\
& Average of snow depth (AWS) & Campbell Scientific SR50-45H \\
\hline \multirow{5}{*}{ IOA/MAWS } & Soil moisture, location A, depth $2 \mathrm{~cm}$ & ThetaProbe ML2X \\
& Soil moisture, location A, depth $10 \mathrm{~cm}$ & ThetaProbe ML2X \\
& Soil moisture, location B, depth $2 \mathrm{~cm}$ & ThetaProbe ML2X \\
& Soil moisture, location B, depth $10 \mathrm{~cm}$ & ThetaProbe ML2X \\
& Air temperature, open area & Pentronic PT100 \\
& Air temperature, forest & Pentronic PT100 \\
& Snow depth, open area (acoustic sensor) & Pentronic PT100 \\
& Snow depth, forest (acoustic sensor) & Campbell Scientific SR50-45H \\
& Snow water equivalent (Gamma Water Instrument) & Astrock Ltd. (experimental) \\
\hline \multirow{2}{*}{ IOA/GWI } & Campbell Scientific SR50-45H \\
\hline
\end{tabular}

specific tests (see Proksch et al., 2015b), the snow profile information should be treated with caution. In addition to temporal variability, also the spatial variability of snow should be considered. As this can be notable even at short distances, it is not recommended to use the measured profiles as they are for direct estimation of snow properties at the instrument footprints. Rather, e.g. Lemmetyinen et al. (2015) applied a simplification of the measured snow profiles to either one or two layers. In addition, a third-order fit was applied to the observations of $E$ to reduce uncertainty arising e.g. from observer bias.

\subsection{Automated in situ data}

Several automatic measurement instruments were installed at the IOA. Two acoustic sensors were used to record SD. One sensor was placed in the forest clearing near the SodRad platform tower and another under the forest canopy at a distance of ca. $50 \mathrm{~m}$. Air temperature $\left(T_{\text {air }}\right)$ was measured at the same locations. Three automated soil moisture and soil temperature measurement sensors were installed at different locations in the test field. Snow water equivalent was measured directly with an experimental device (GWI, Gamma Water Instrument). Data from other automated in situ observations were collected into the consolidated datasets from the FMI sounding station (ca. $500 \mathrm{~m}$ from the IOA). The automated data available in the consolidated datasets are summarized in Table 3 .

\subsection{Intensive observation periods}

Intensive observation periods (IOPs) were organized during the first three NoSREx campaigns. The objective of the IOPs was to complement the collected time series of basic observations, in particular by employing advanced methods for characterization of snow microstructure. The measurements consisted of

- SSA analyses using near-infrared (NIR) photography (Matzl et al., 2006),

- snow micropenetrometry using the Snow MicroPen, (SMP; Schneebeli et al., 1998; Proksch et al., 2015a),

- computer tomography (CT) analysis of casted snow samples (Matzl et al., 2010).

In particular, the measurements provide a means to validate visual estimations of layering against SMP profiles, validate and compare visual grain size estimates against correlation length from CT imagery, validate density profile measurements against density profile from CT analysis and estimate the 3-D distribution on main sites' snow stratigraphy from SMP measurements surrounding the test field.

The data can be used to drive forward models for emission and backscatter directly for the date when measurements are available, providing a possibility to accurately study the effect of small-scale snow characteristics on emission and 
backscatter. As in the case of conventional snow pit observations, most measurements were made outside of the instrument footprints. However, as a one-time test during the third campaign period, SMP measurements and casted CT samples were taken from an area in the test field observed by both SnowScat and SodRad (Proksch et al., 2015). Data from IOPs are not a part of the NoSREx consolidated datasets but can be made available on request from FMI.

\section{NoSREx consolidated datasets}

The key observations of NoSREx are collected in a consolidated dataset, providing easy access to the main time series of in situ and microwave measurements. The data are provided as csv (comma-separated value) files and Excel spreadsheets. The data include

- calibrated time series of SnowScat backscatter sigma nought at four incidence angles $\left(30,40,50,60^{\circ}\right)$ and three $2 \mathrm{GHz}$ frequency bands (centre frequencies: 10.2 , 13.3 and $16.7 \mathrm{GHz}$ ). Separate data files are provided for the two measurement sectors (sector 1: main measurement sector; sector 2: adjacent sector). Data are provided as averages over the full azimuth scan range of both sectors, with the exception that some azimuth directions have been removed from the sector 1 data to avoid experimental plate targets set in 2010. Note that SnowScat consolidated data for NoSREx III (20112012) are limited to a period after 20 January 2012, due to observed anomalies in the backscatter data.

- calibrated time series of SodRad brightness temperatures at 10.65, 18.7, 37 and $90 \mathrm{GHz}, \mathrm{H}$ and $\mathrm{V}$ pol, at four incidence angles $\left(30,40,50,60^{\circ}\right)$. Average value and standard deviation of each elevation scan provided. The $90 \mathrm{GHz}$ receiver was replaced by a $21 \mathrm{GHz}$ receiver from autumn 2011 onwards.

- time series of selected automated in situ observations at the IOA, the main FMI-ARC automated weather station (AWS), the meteorological mast. Data are provided as average values over the scan times ( 3 or $4 \mathrm{~h}$ ) of SnowScat observations. Recently, an updated version with $1 \mathrm{~h}$ averages has been made available.

- Summary of weekly and bi-weekly manual snow pit measurements at the IOA.

\section{Overview of collected data from NoSREx I to IV}

The NoSREx campaign seasons each had distinctive characteristics concerning weather conditions, snow structure and soil conditions. All of these affected the resulting microwave signatures, which are discussed in this section.

\subsection{Weather and snow conditions}

The four winter seasons covered by NoSREx are summarized in the following in terms of weather, snow and soil conditions. The distinctive characteristics of each season of NoSREx are collected in Table 4, showing also a comparison to the 30-year average in the Sodankylä region. The date of the onset of soil freezing, maximum frost depth, onset of soil thaw and maximum frost depth are given. Regarding snow conditions, the seasons are compared for the date of permanent snow cover, date of maximum SWE, date of snowmelt onset, maximum SWE, and average snow density and grain size. The data are compiled based on both automated and manual observations. Two metrics related to the temperature gradient between the top and bottom of the snowpack are given, i.e. the average temperature gradient between air and soil $\left(<\Delta T>=<T_{\text {air }}-T_{\mathrm{G}}>\right.$ ) and the effective sum of the mean daily temperature gradient, defined here as the sum of daily average temperature gradients divided by the respective daily mean snow depth.

For the NoSREx I, the early onset of permanent snow cover (day of year (DOY) 279) and mild temperatures were clearly linked to a delayed evolution of soil freezing. Meltrefreeze events in December also caused the formation of a crust at the bottom of the snowpack. The maximum measured SWE was slightly over the 30-year average, while, based on snow pit observations, depth hoar was largely absent. The following season (NoSREx II) saw a sharp onset of soil freezing; at its maximum, the measured soil frost depth was over $2 \mathrm{~m}$ in March-April 2011. The season saw harsh temperatures in early winter and a relatively thin snow cover, with a maximum SWE of only $165 \mathrm{~mm}$, the lowest maximum value for the 3 years investigated. This caused rapid freezing of the soil as well as the formation of a distinct depth hoar layer in the snow, which is exhibited by the highest average and effective sum of the temperature gradient, and the largest average estimated snow grain size. The average bulk snow density was also notably low $\left(170 \mathrm{~kg} \mathrm{~m}^{-3}\right)$.

Despite late onset of permanent snow cover (DOY 329), the third season of observations (NoSREx III) saw the thickest snow cover of the campaign, with a maximum recorded SWE value of $240 \mathrm{~mm}$, and the lowest penetration of soil freezing, the largest measured value being $120 \mathrm{~cm}$. The early season was exceptionally mild in temperatures, resulting in the lowest average and smallest effective sum of the temperature gradient of the four compared seasons. The thermal winter began later than during the previous 2 years, with a relatively thick snowpack already present. As a result, the development of soil frost was initially slow, and soil temperature remained at $\sim 0{ }^{\circ} \mathrm{C}$ well past the beginning of February (see Fig. 2c), indicating residual free water in the top soil. Snow pit information indicated that the formation of depth hoar was very weak early in the season, due to the small temperature gradient between the top and bottom of the snowpack. Despite the subjective nature of visual grain size esti- 
Table 4. Summary of seasonal characteristics for soil and snow conditions in winter periods of 2009-2010, 2010-2011 and 2011-2012, compared to 30-year average in the Sodankylä region. Data are compiled based on both automated and manual observations.

\begin{tabular}{|c|c|c|c|c|c|c|}
\hline & Season & 30-year average & 2009-2010 & 2010-2011 & $2011-2012$ & 2012-2013 \\
\hline \multirow{5}{*}{ Soil conditions } & Onset of soil freezing (DOY) & 298 & 289 & 289 & 320 & 298 \\
\hline & Date of maximum frost depth (DOY) & 91 & 91 & 90 & 107 & 106 \\
\hline & Onset of soil thaw (DOY) & 132 & 126 & 116 & 132 & 121 \\
\hline & Date of soil thaw (DOY) & 148 & 141 & 152 & 147 & 146 \\
\hline & Max frost depth $(\mathrm{cm})$ & 160 & 161 & 210 & 115 & 155 \\
\hline \multirow{7}{*}{ Snow conditions } & Date of permanent snow cover (DOY) & 299 & 279 & 300 & 329 & 289 \\
\hline & Date of SWE maximum (DOY) & 109 & 88 & 72 & 112 & 102 \\
\hline & Date of snowmelt onset (DOY) & NA & 90 & 92 & 115 & 102 \\
\hline & Date of snow melt-off (DOY) & 129 & 134 & 128 & 140 & 133 \\
\hline & Max SWE (mm) & $\begin{array}{l}186.5 \pm 41.9 \text { standard deviation } \\
\text { (record } \min 120 ; \text { record } \max 267 \text { ) }\end{array}$ & 225 & 165 & 240 & 191 \\
\hline & Average density $\left(\mathrm{kg} \mathrm{m}^{-3}\right)$ & Not available (NA) & 200 & 170 & 190 & 200 \\
\hline & $\begin{array}{l}\text { Grain size (Fiertz et al., 2009); } \\
\text { depth-weight average } \pm \text { standard deviation }(\mathrm{mm})\end{array}$ & NA & $1.4 \pm 0.2$ & $1.5 \pm 0.3$ & $0.9 \pm 0.3$ & $1.1 \pm 0.3$ \\
\hline \multirow{2}{*}{ Temperature } & $\begin{array}{l}\text { Mean temperature gradient; } \\
<\Delta T>=<T_{\text {air }}-T_{\mathrm{G}}>\left({ }^{\circ} \mathrm{C}\right)\end{array}$ & NA & -8.7 & -10.0 & -8.3 & -9.4 \\
\hline & $\begin{array}{l}\text { Effective sum of daily } \\
\text { mean temperature gradient* }\end{array}$ & NA & 26.3 & 43.0 & 22.8 & 30.5 \\
\hline
\end{tabular}

$* \sum_{d=1}^{N}<\Delta T_{d} / \mathrm{SD}_{d}>$.

mates, it can be concluded that the average grain size of the snow was clearly smaller during NoSREx III than the preceding two seasons, largely due to the absence of large depth hoar crystals in the dataset.

The fourth season (NoSREx IV) exhibited soil and snow conditions close to the 30 -year average. Compared to preceding seasons, the estimates of snow grain size were on average the smallest after NoSREx III ( $E=1.1 \pm 0.3 \mathrm{~mm})$, while the SWE maximum fell between the first and second seasons.

\subsection{Microwave signatures against snow and soil conditions}

Figure 2 presents the time series of observations for the four seasons of NoSREx, summarizing some of the microwave and in situ information available. Co-polarized (VV polarization) backscatter measurements at $50^{\circ}$ incidence angle from the SnowScat instrument are shown. The data are integrated over three $2 \mathrm{GHz}$ frequency bands (centre frequencies at 10.2, 13.3 and 16.7 GHz). Vertically polarized SodRad observations at 18.7 and $37 \mathrm{GHz}$, typically used for detection of snow water equivalent, are displayed for the same time periods. Selected in situ observations include SD, air temperature $\left(T_{\text {air }}\right)$, ground temperature $\left(T_{\mathrm{G}}\right)$, bulk averages of manually measured snow density $\left(\rho_{\mathrm{S}}\right)$ and bulk averages of visual estimates of $E$. The microwave instruments suffered from installation delays and malfunctions, which appear as data gaps in the autumn seasons of 2009, 2011 and 2012. Specialized tests and maintenance periods took place also in April 2010, April 2012 and February/March 2013. Notably, continuous measurements from snow-free conditions to snow melt-off from both SnowScat and SodRad are available only for NoSREx II.

The microwave signatures reveal some interesting characteristics; in particular, the early snow season response was characterized by sudden decreases in backscatter, originating from snowmelt events (Mätzler and Schanda, 1984), followed by an increase in backscatter during refreezing. Several such periods occurred e.g. in the autumns of 2009 and 2010; for 2010, the same features can be observed in SodRad brightness temperatures. A distinct feature observed during NoSREx I, II and IV was a gradual decrease of backscatter after the initial increase (measurements during the early winter of NoSREx III, until January 2012, were lost due to an erroneous setting in the SnowScat instrument). The effect can be explained by the gradual relaxation of crust structures in snow, formed during the early-season melt events and causing increased backscatter (e.g. Strozzi et al., 1997), to more typical late-winter snow. The fact that the effect is more discernible at $16.7 \mathrm{GHz}$ than at the two lower frequency bands implies that the feature is dominated by scatter changes in the snow volume. Unfortunately, the in situ data were not able to provide a quantitative measure of the phenomena, as objective measurements of the snow structure (e.g. computer tomography samples; see Sect. 2.6) were not taken in the early season. Nevertheless, the observations are consistent with the expected backscatter behaviour of snow undergoing metamorphism (e.g. Lin et al., 2016).

Overall, there is very low response at X-band $(10.2 \mathrm{GHz})$ to changing snow conditions during the entire snow season, with signatures during NoSREx I and III even showing a continuous decreasing trend in backscattering intensity. The response at the low $\mathrm{Ku}$-band $(13.3 \mathrm{GHz})$ shows some increase 

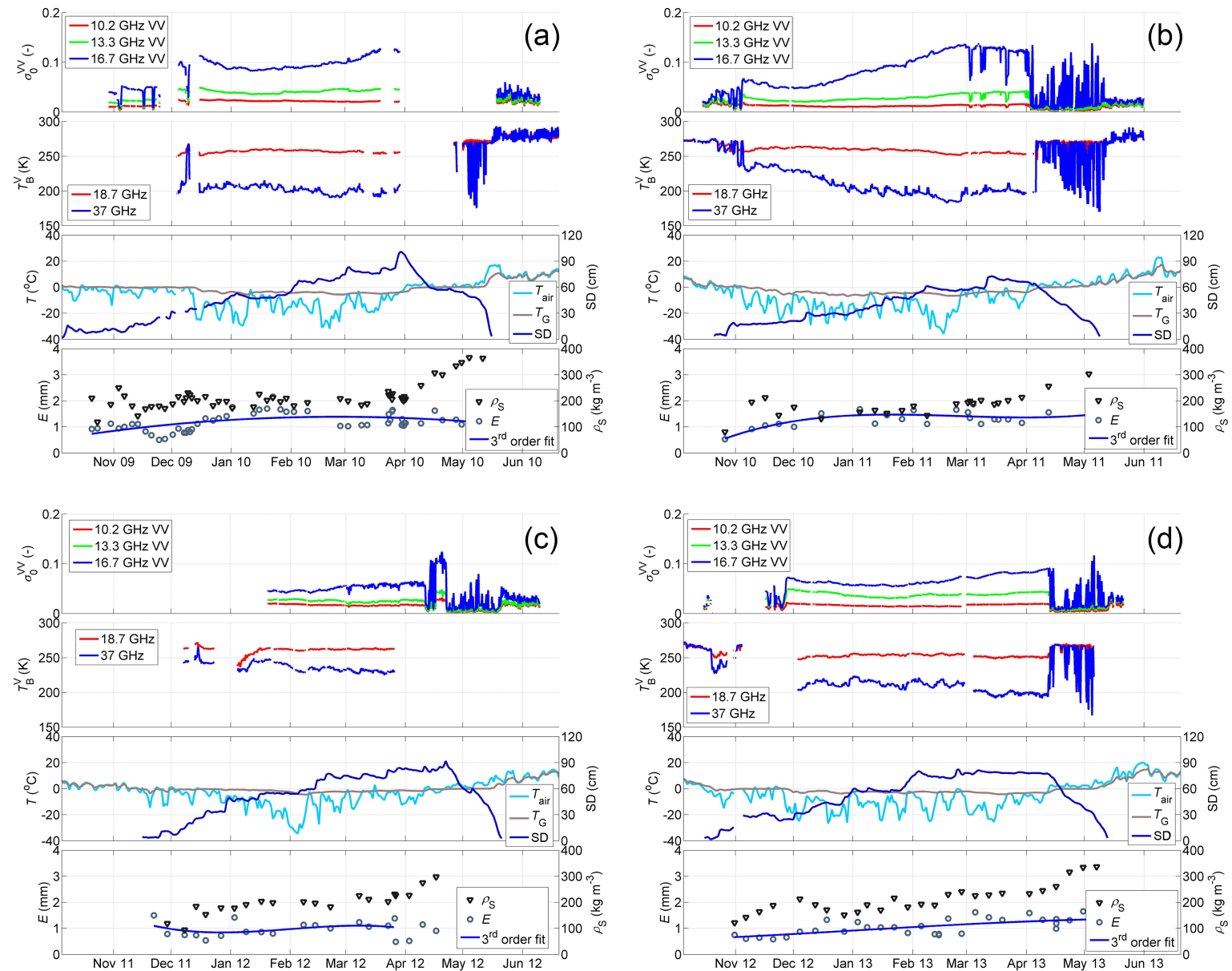

Figure 2. Summary of NoSREx seasons I-IV (a-d). Panels from SnowScat VV-polarized backscattering 50 incidence angle; SodRad brightness temperatures at 18.7 and $37 \mathrm{GHz}$, vertical polarization, $50^{\circ}$ incidence angle; snow depth (SD), air temperature $\left(T_{\text {air }}\right)$ and ground temperature $\left(T_{\mathrm{G}}\right)$; bulk averages of manually measured snow density $\left(\rho_{\mathrm{S}}\right)$ and visual estimates of snow grain size $(E)$. Third-order fit to time series of $E$ shown.

in intensity during NoSREx I and II, while for NoSREx III (Fig. 2c) no increase is apparent. A notable response at the higher Ku-band (16.7 GHz) is observed for NoSREx I, II and IV. However, in particular during the last season the increase in backscattering cannot be attributed to increase in snow mass, as the measured snow height and density remained almost constant from March to April 2013, when an increase of Ku-band backscattering was observed. Rather, the increase can be related to the observed increase in snow grain size.

The measured SodRad brightness temperature response showed clear similarities with the backscatter measured by SnowScat. In particular, the dynamic responses of both the 18.7 and $37 \mathrm{GHz}$ channels were strongest for the latter (Fig. 2b) and notable also for NoSREx I (Fig. 2a; note: earlyseason dynamics not visible due to late start of measurements). Signal dynamics at $37 \mathrm{GHz}$ were much reduced during NoSREx III (Fig. 2c), indicating a low amount of total scattering in the snowpack, despite the 3rd year exhibiting the highest total SWE.
It should be noted that, for NoSREx I and III, measurements had begun only after the onset of snow cover. Furthermore, in November 2012, SodRad measurements were halted due to maintenance immediately after the onset of snow cover. The early-season drop of the $37 \mathrm{GHz}$ brightness temperature is thus not apparent in the data for those seasons. The SodRad instrument also malfunctioned in early April 2012, missing the last significant increase in SWE of the season.

The small average $E$ during NoSREx III $(0.9 \mathrm{~mm}$, compared to 1.4 and $1.5 \mathrm{~mm}$ for NoSREx I and II, respectively), originating from distinct snow cover and temperature conditions, may explain in part the diminished dynamics of the backscatter and emission signals observed during this season. The low bulk average value of $E$ reflects mainly the lack of a depth hoar layer during NoSREx III, whereas for NoSREx II a significant layer of depth hoar was observed. For NoSREx I, large grains were prominent in the lower snow layers due to early formation of melt-refreeze crusts. 
A declining trend towards the late season can be observed in the third-order fit of E in particular for NoSREx I and II (Fig. 2a and b); this can be explained by newly fallen layers of snow with a small grain size forming an increasingly large part of the total snowpack, thus affecting the bulk average. For NosREx IV (Fig. 2d), the average grain size was observed to increase almost monotonously for the entire dry-snow season. This may explain why both the $16.7 \mathrm{GHz}$ backscattering and $37 \mathrm{GHz}$ emission signatures continue to indicate increasing scattering in the snow, despite the snow height remaining almost constant between March and April 2013.

\section{Model analysis}

To demonstrate the use of the NoSREx data in evaluation of microwave emission and backscattering models, the Microwave Emission Model for Layered Snowpacks adapted to include backscattering (MEMLS3\&a) consisting of simulation of both active and passive microwave response (Wiesmann and Mätzler, 1999; Mätzler and Wiesmann, 1999; Proksch et al., 2015b) was applied.

\subsection{Model configuration}

The expected backscatter and emission response with measured snow and soil conditions was simulated for all four seasons of NoSREx using a one-layer model configuration. Daily simulations were performed using the daily averages of measured SD, $\rho_{\mathrm{S}}, T_{\mathrm{G}}, T_{\text {air }}$ (see Fig. 2) and snow exponential correlation length $\left(p_{\mathrm{ex}}\right)$, obtained from $E$ using an empirical relation introduced by Durand et al. (2008). Both $\rho_{\mathrm{S}}$ and $E$ were obtained from weekly manual snow measurements; thus, a third-order fit was applied to the measurement time series to obtain daily values (see Fig. 2 for fit to measurements of $E$ ). This was also necessary to reduce the random variability of the manual measurements.

The calculated value for $p_{\text {ex }}$ was further modified in simulations by using a seasonal linear scaling factor to obtain an optimized correlation length $p_{\mathrm{ex}}^{\mathrm{opt}}\left(p_{\mathrm{ex}}^{\mathrm{opt}}=\beta \cdot p_{\mathrm{ex}}\right)$. The vertically polarized brightness temperatures at 18.7 and $37 \mathrm{GHz}$ were matched to observations using the scaling factor $\beta$; these channels were assumed to be least affected by snow layering as well as roughness variations at the snow-soil interface. The use of the scaling factor allowed assessing the validity of the model over the other orthogonal polarization for simulating brightness temperature, as well as for simulating backscattering, while using the same model configuration. The obtained values for $\beta$, obtained iteratively at 0.05 increments, ranged from 0.9 for NoSREx I to 1.3 for NoSREx II and IV. It can be assumed that the scaling accounts for shortcomings in both model physics and the available input information.
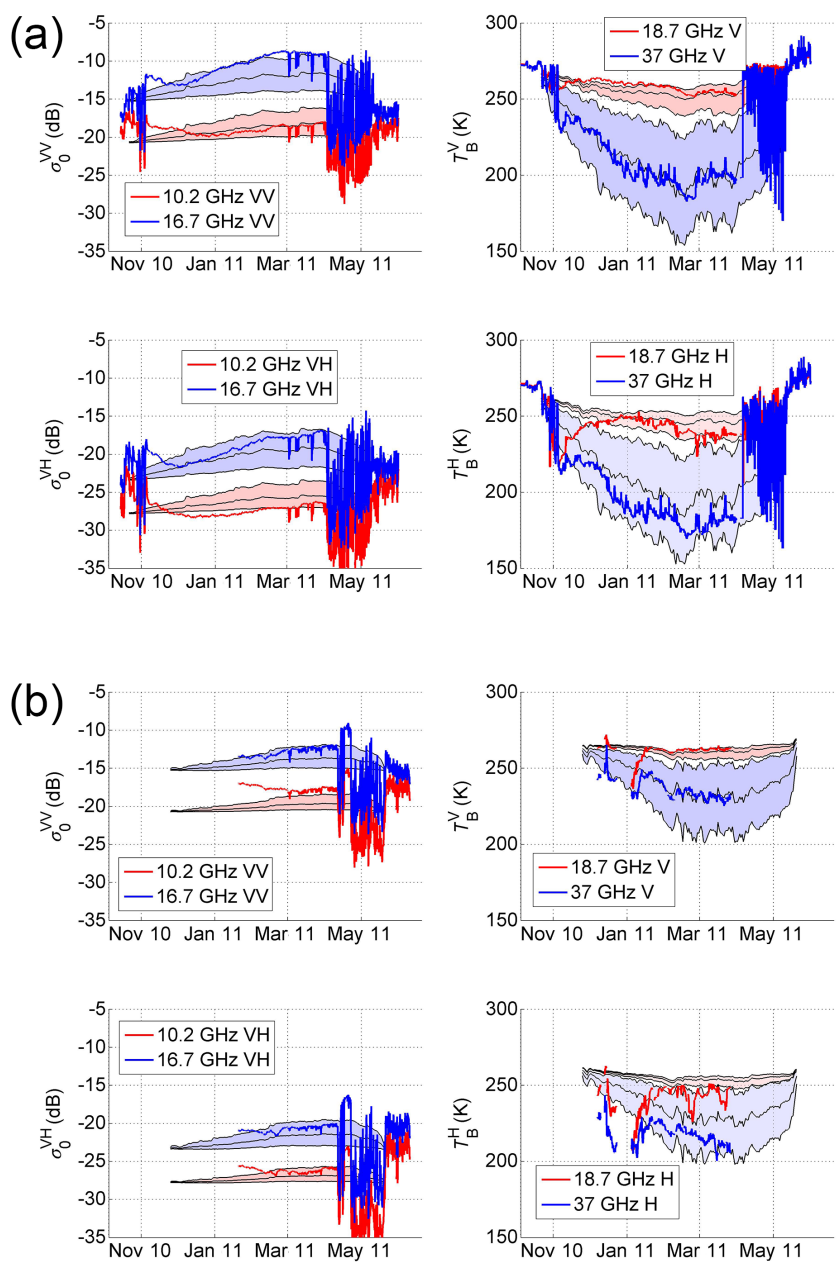

Figure 3. Comparison of modelled (shaded areas) and measured (solid lines) response of backscatter and brightness temperature during NoSREx seasons II and III (a and b). Simulations in a one-layer configuration using MEMLS3\&a (Proksch et al., 2015b) for $50^{\circ}$ incidence angle, applying measured parameters depicted in Fig. 2. Scattering coefficient estimated using the improved Born approximation (Mätzler and Wiesmann, 1999). Simulation optimized for vertically polarized brightness temperature $\left(T_{\mathrm{B}}^{\mathrm{V}}\right)$ by using seasonal scaling factor to snow exponential correlation length $p_{\mathrm{ex}}$. Simulation error limits calculated by modifying $p_{\text {ex }}$ by $\pm 30 \%$.

Soil reflectivity was estimated based on early-season observations of NoSREx II, resulting in reflectivity values from 0.02 to 0.04 and 0.03 to 0.05 for vertically and horizontally polarized reflectivity, respectively. For the active model, the specular part of the reflection was set at 0.7 and 0.3 for $\mathrm{X}$ and Ku-band, respectively, and the cross-polarization ratio was assumed as 0.15 . The mean slope of surface undulations was set at 0.05 . The soil roughness parameters were kept constant for all four seasons. In brightness temperature simulations, downwelling sky brightness temperature (atmosphere + cosmic background) was estimated as 18 and $38 \mathrm{~K}$ for 18.7 and $37 \mathrm{GHz}$, respectively. 
Table 5. Summary of MEMLS3\&a simulation bias and unbiased RMSE for 10.2 and $16.7 \mathrm{GHz}$ backscattering (above) and 18.7 and $37 \mathrm{GHz}$ brightness temperature (below) against observations from SnowScat and SodRad instruments. Results over the dry-snow period $\left(T_{\text {air }}<-1{ }^{\circ} \mathrm{C}\right.$ ) for NoSREx seasons I to IV. Simulations were optimized against $T_{\mathrm{B}}^{\mathrm{V}}$ using a seasonal scaling factor $\beta$ to $p_{\mathrm{ex}}$ (2009-2010: $\beta=1.25 ; 2010-201: \beta=1.3 ; 2011-2012: \beta=0.9 ; 2012-2013: \beta=1.3$ ).

\begin{tabular}{|c|c|c|c|c|c|c|c|c|}
\hline \multirow{2}{*}{$\begin{array}{l}\sigma^{0} \\
\text { Season }\end{array}$} & \multicolumn{2}{|c|}{$10.2 \mathrm{GHz}$ VV } & \multicolumn{2}{|c|}{$10.2 \mathrm{GHz} \mathrm{VH}$} & \multicolumn{2}{|c|}{$16.7 \mathrm{GHz} \mathrm{VV}$} & \multicolumn{2}{|c|}{$16.7 \mathrm{GHz} \mathrm{VH}$} \\
\hline & Bias (dB) & uRMSE (dB) & Bias (dB) & uRMSE (dB) & Bias (dB) & uRMSE (dB) & Bias $(\mathrm{dB})$ & uRMSE (dB) \\
\hline 2009-2010 & -2.1 & 0.7 & -0.3 & 0.5 & -2.0 & 0.7 & -2.1 & 0.6 \\
\hline $2010-2011$ & -0.1 & 0.9 & 1.0 & 1.1 & -1.9 & 1.0 & -1.1 & 1.1 \\
\hline 2011-2012 & -2.4 & 0.6 & -1.0 & 0.7 & -1.3 & 0.7 & -1.2 & 0.8 \\
\hline 2012-2013 & -1.0 & 0.9 & 1.1 & 0.8 & -0.6 & 0.8 & -0.4 & 1.4 \\
\hline$T_{\mathrm{B}}$ & \multicolumn{2}{|c|}{$18.7 \mathrm{GHz} \mathrm{V}$} & \multicolumn{2}{|c|}{$18.7 \mathrm{GHz} \mathrm{H}$} & \multicolumn{2}{|c|}{$37 \mathrm{GHz} \mathrm{V}$} & \multicolumn{2}{|c|}{$37 \mathrm{GHz} \mathrm{H}$} \\
\hline Season & Bias $(\mathrm{K})$ & uRMSE (K) & Bias $(\mathrm{K})$ & uRMSE (K) & Bias $(\mathrm{K})$ & uRMSE (K) & Bias (K) & uRMSE (K) \\
\hline 2009-2010 & -2.8 & 2.2 & 13.4 & 7.3 & 1.9 & 4.3 & 15.9 & 6.7 \\
\hline 2010-2011 & -3.4 & 3.2 & 7.4 & 8.8 & 0.5 & 6.4 & 11.8 & 7.8 \\
\hline 2011-2012 & 0.9 & 5.3 & 13.5 & 9.1 & 3.4 & 5.7 & 17.6 & 9.6 \\
\hline $2012-2013$ & 2.8 & 3.4 & 20.4 & 6.2 & -0.7 & 9.5 & 13.1 & 7.4 \\
\hline
\end{tabular}

\subsection{Comparison to observations}

The result of the model estimates against 10.2 and $16.7 \mathrm{GHz}$ VV- and VH-polarized backscatter measured by SnowScat (in $\mathrm{dB}$ ) and 18.7 and $37 \mathrm{GHz} \mathrm{H}$ - and V-polarized brightness temperature (in Kelvin) observed by SodRad are presented in Fig. 3 for NoSREx seasons II and III. As explained in Sect. 4.2, these two seasons differed most in terms of snow properties (SWE and grain size). In order to illustrate the effect of snow microstructure on simulations, these are depicted as a shaded area corresponding to fluctuating $p_{\text {ex }}$ by $\pm 30 \%$ (corresponding to the highest scaling factor applied for model optimization).

Applying the optimization of the model described above, simulations of $T_{\mathrm{B}}$ at both $\mathrm{V}$ and $\mathrm{H}$ polarizations reproduce the observed trends with reasonable accuracy during both seasons. Short-term fluctuations at both polarizations are driven mainly by physical temperature of soil and snow, while the overall signal dynamics are governed by snow accumulation and microstructure. The differences in seasonal dynamics between the two seasons are well apparent, with the minimum $T_{\mathrm{B}}^{\mathrm{V}}$ at $37 \mathrm{GHz}$ reaching $170 \mathrm{~K}$ for NoSREx II, while equivalent minimum values for NoSREx III were above $230 \mathrm{~K}$.

Simulations of the active microwave response similarly highlight differences between the two seasons; for NoSREx II, the simulated backscattering increases by ca. $3 \mathrm{~dB}$ for Ku-band and $2 \mathrm{~dB}$ for X-band VV polarization throughout the dry-snow season. For NoSREx III, the simulated increase was only 1.5 and $1 \mathrm{~dB}$ for X- and Ku-band, respectively. Here, applying the optimized scaling factor for $p_{\mathrm{ex}}$ did not fully account for the measured increase in Ku-band $(16.7 \mathrm{GHz})$ backscattering during NoSREx II, resulting in an increasing underestimation towards the end of the season. The X-band $(10.2 \mathrm{GHz})$ response, however, was better cap- tured. For NosREx III, the measured seasonal dynamic response was closer to the simulations, while the X-band simulations were underestimated. It is also notable that the singlelayer simulations could not reproduce the sharp increase of the backscatter signal observed for NoSREx II after earlyseason melt-refreeze events.

Table 5 summarizes the bias and root mean square errors (RMSEs) (with bias removed) of simulated backscatter and brightness temperature against measurements separately for each of the four seasons of NoSREx. The analysis is limited to the dry-snow period, defined here as days with snow depth over $5 \mathrm{~cm}$ and mean air temperature below $-1{ }^{\circ} \mathrm{C}$. As the simulation was optimized for 18.7 and $37 \mathrm{GHz} \mathrm{V} \mathrm{pol} \mathrm{bright-}$ ness temperature, these channels exhibit the lowest bias. A residual RMSE of over $5 \mathrm{~K}$ and up to $10 \mathrm{~K}$ remains for these channels, respectively. The errors at $\mathrm{H}$ polarization are notably larger for both frequencies, with a positive bias (overestimation) up to over $20 \mathrm{~K}$. This plausibly results from the higher sensitivity of horizontal polarization to snow layering effects (see e.g. Rees et al., 2010), which are omitted in the one-layer model configuration. Bias errors from -2.4 to $1.1 \mathrm{~dB}$ were obtained for the simulated backscatter values, using the scaled $p_{\mathrm{ex}}$ values; the magnitude of the bias varied from season to season for each channel with no notable pattern. The unbiased RMSEs for VV polarization were below $1.0 \mathrm{~dB}$ for all cases, while the cross-polarized channels exhibited slightly larger errors (up to $1.4 \mathrm{~dB}$ ) for NoSREx II and IV. A large part of the remaining unbiased RMSEs were due to the early-season discrepancy of the simulation, which was unable to replicate the detected sharp increase in backscattering due to melt-refreeze events. For the January-March period, the unbiased RMSE was less than $0.7 \mathrm{~dB}$ for all channels. 


\section{Discussion}

Using data collected during NoSREx, Lin et al. (2016) demonstrated that snow microstructural morphology was a major driver for large variations from year-to-year dynamics of the radar backscattering signal vs. SWE, and the signal was further affected by early-season melt-refreeze events which varied from one season to another. Regarding possibilities for retrieval of SWE, Lin et al. (2016) conclude that the complexity of the radar signal leads to stringent requirements for a priori knowledge on the snowpack states, as well as backscattering models to account for snow microstructural temporal variations.

In this regard, the NoSREx dataset provides some interesting insight into possibilities of using active and passive microwave systems in synergy to retrieve information on snow cover. Analysis of the datasets in this study indicated that the differences in both active and passive microwave dynamic response over the different seasons can largely be attributed to differences in snow microstructural properties, which affected the scattering efficiency of the snowpack. In a preliminary model analysis using the MEMLS3\&a active/passive model, these signatures could also be replicated with reasonable accuracy for radar backscattering when the passive microwave signature was first optimized using the snow correlation length (i.e. microstructure). This suggests the possibility of parametrizing the retrieval of snow parameters such as SWE in terms of snow microstructural properties, by exploiting information provided by active and passive microwave sensors in unison. However, the analysis shows also that, when using a one-layer configuration, the MEMLS3\&a model may not correctly reproduce backscattering signatures in particular during the early snow season. Multi-layer retrieval configurations supported by e.g. physical snow models for initializing snowpack states should be investigated to overcome this deficiency.

Snow grain size, which presents the main source of information on snow microstructure for NoSREx, is particularly difficult to establish in the field. Research also indicates that the grain size by itself is insufficient to explain the full scattering behaviour of microwaves in snow (e.g. Mätzler, 2002). The problem is aggravated by snow particles of increasing size and complex shape, as well as by sintering and clustering of snow grains. However, using data collected during NoSREx, Leppänen et al. (2015) demonstrated that visually established grain sizes $E$ correlated with optical grain sizes measured using an objective measure of SSA. Furthermore, Lemmetyinen et al. (2015) showed that an average grain size used to fit emission model predictions captured both the magnitude and the seasonal trend of the visually estimated grain sizes during NoSREx-II. Therefore, the information collected on $E$ can be used at least as an indicator of snow microstructural evolution during the NoSREx campaigns, even if not employed directly in e.g. forward-model simulations of emission and backscattering.
Overall, the NoSREx data have already proven useful for establishing novel relations between snow properties and microwave signatures. Chang et al. (2015) applied the SnowScat observations for comparisons of backscattering estimates using two derivations of the dense media radiative transfer (DMRT), the bicontinuous model and quasi-crystalline approximations (QCAs). The bicontinuous approach is based on exact solutions of the Maxwell equations, while QCA is an analytical approximation. Both approaches showed reasonable agreement with SnowScat observations collected during the second campaign season. Furthermore, Tan et al. (2015) recently demonstrated the necessity of multiplescattering enhancement in DMRT, using both active and passive observations from NoSREx for model evaluation. On the other hand, Leinss et al. (2015) applied SnowScat observations for differential interferometry, showing that the increase in SWE could be accurately obtained by exploiting the phase information retained in SnowScat observations. The high temporal resolution of SnowScat (3-4h) allowed mitigating decorrelation effects, while phase wrapping at the relatively high frequencies was addressed with a novel twofrequency approach. Data collected in the frame of NoSREx have also been exploited in recent studies focused on passive microwave signatures (e.g. Rautiainen et al., 2014; Pan et al., 2015).

\section{Conclusions}

The NoSREx campaign provides a nearly continuous time series of active and passive microwave signatures of seasonal snow cover in a natural environment over four winter seasons. The dataset is unique in providing signatures over several winter seasons from the same site, with each season exhibiting singular characteristics in both microwave backscattering and emission, as well as snow and soil properties. The dataset is freely available to science users (see the Data availability section). Analysis of NoSREx datasets has already revealed several features of interest relating snow properties to the backscatter and emission, and the dataset has seen wide use in the field of developing advanced forward models for remote-sensing observables in the microwave range. In particular, the collected data and the analysis provided in this study using the MEMLS3\&a model corroborate previous findings that correct determination of the snow microstructure is imperative for understanding microwave signatures. Future campaigns should increasingly make use of advanced methodologies for quantifying snow structural properties, including the snow microstructure. This will enable developing new metrics relating snow properties to microwave signatures obtained from Earth-observing satellites. 


\section{Data availability}

The NoSREx consolidated datasets are available after registration on the ESA Earth Observations Campaign Data portal (https://earth.esa.int/web/guest/campaigns). SnowScat raw data are available for scientific use via FMI and GAMMA Remote Sensing AG. Data from NoSREx IOPs are available for scientific use on request from WSL-SLF. The time series of SSA profiles are available on separate request from FMI.

Acknowledgements. The work was conducted under the European Space Agency project "Technical assistance for the deployment of an X- to Ku-band scatterometer during the NoSREx experiment" (ESA ESTEC contract 22671/09/NL/JA/ef). The staff at FMI-ARC are acknowledged for in situ data collection and operation of microwave instruments.

Edited by: Mark Paton

Reviewed by: two anonymous referees

\section{References}

Barnett, T. P., Adam, J. C., and Lettenmaier, D. P.: Potential impact of a warming climate on water availability in snow-dominated regions, Nature, 438, 303-309, 2005.

Brasnett, B.: A global analysis of snow depth for numerical weather prediction, J. Appl. Meteorol., 38, 726-740, doi:10.1175/15200450(1999)038<0726:AGAOSD>2.0.CO;2, 1999.

Chang, W., Tan S., Lemmetyinen J., Tsang, L., Xu, X., and Yueh, S.: Dense Media Radiative Transfer Applied to SnowScat and SnowSAR, IEEE J. Select. T. App. Earth Obs. Remote Sens., 7, 3811-3825, doi:10.1109/JSTARS.2014.2343519, 2015.

Derksen, C. and Brown, R.: Spring snow cover extent reductions in the 2008-2012 period exceeding climate model projections, Geophys. Res. Lett., 39, L19504, doi:10.1029/2012GL053387, 2012.

Durand, M., Kim, E. J., and Margulis, S. A.: Quantifying uncertainty in modelling snow microwave radiance for a mountain snowpack at the point-scale, including stratigraphic effects, IEEE T. Geosci. Remote, 46, 1753-1757, 2008.

ESA: Report for Mission Selection: CoReH2O, ESA SP-1324/2 (3 volume series), European Space Agency, Noordwijk, The Netherlands, 2012.

Fierz, C., Armstrong, R. L., Durand, Y., Etchevers, P., Greene, E., McClung, D. M., Nishimura, K., Satyawali, P. K., and Sokratov, S. A.: The International Classification for Seasonal Snow on the Ground. IHP-VII Technical Documents in Hydrology no. 83, IACS contribution no. 1, UNESCO-IHP, Paris, 2009.

Gallet, J.-C., Domine, F., Zender, C. S., and Picard, G.: Measurement of the specific surface area of snow using infrared reflectance in an integrating sphere at 1310 and $1550 \mathrm{~nm}$, The Cryosphere, 3, 167-182, doi:10.5194/tc-3-167-2009, 2009.

Groisman, P. Y., Karl, T. R., and Knight, R. W.: Observed impact of snow cover on the heat balance and the rise of continental spring temperatures, Science, 263, 198-200, 1994.
Kelly, R., Chang, A., Tsang, L., and Foster, J.: A prototype AMSRE global snow area and snow depth algorithm, IEEE T. Geosci. Remote, 41, 230-242, 2003.

Leinss, S., Wiesmann, A., Lemmetyinen, J., and Hajnsek, I.: Snow Water Equivalent of dry snow measured by differential interferometry, IEEE J. Select. T. App. Earth Obs. Remote Sens., 8, 3773-3790, 2015.

Lemmetyinen, J., Derksen, C., Toose, P., Proksch, M., Pulliainen, J., Kontu, A., Rautiainen, K., Seppänen, J., and Hallikainen, M.: Simulating seasonally and spatially varying snow cover brightness temperature using HUT snow emission model and retrieval of a microwave effective grain size, Remote Sens. Environ., 156, 71-95, 2015

Lemmetyinen, J., Schwank, M., Rautiainen, K., Kontu, A., Parkkinen, T., Mätzler, C., Wiesmann, A., Wegmüller, U., Derksen, C., Toose, P., Roy, A., and Pulliainen, J.: Snow density and ground permittivity retrieved from L-band radiometry: Application to experimental data, Remote Sens. Environ., 180, 377-391, 2016.

Leppänen, L., Kontu, A., Vehviläinen, J., Lemmetyinen, J., and Pulliainen, J.: Comparison of traditional and optical grain size field measurements with SNOWPACK simulations in a taiga environment, J. Glaciol., 61, 151-162, 2015.

Leppänen, L., Kontu, A., Hannula, H.-R., Sjöblom, H., and Pulliainen, J.: Sodankylä manual snow survey program, Geosci. Instrum. Method. Data Syst., 5, 163-179, doi:10.5194/gi-5-1632016, 2016.

Lin, C.-C., Rommen, B., Floury, N., Schüttemeyer, D., Davidson, M., Kern, M., Kontu, A., Lemmetyinen, J., Pulliainen, J., Wiesmann, A., Werner, C., Mätzler, C., Schneebeli, M. Proksch, M., and Nagler, T.: Active microwave scattering signature of snowpack - continuous multi-year SnowScat observation experiments, J. Sel. Top. App. Earth Obs. Remote Sens., 99, 1-21, doi:10.1109/JSTARS.2016.2560168, 2016.

Matzl, M. and Schneebeli, M.: Measuring specific surface area of snow by near-infrared photography, J. Glaciol., 52, 558-564, 2006.

Matzl, M. and Schneebeli, M.: Stereological measurement of the specific surface area of seasonal snow types: Comparison to other methods, and implications for mm-scale vertical profiling, Cold Reg. Sci. Technol., 64, 1-8, 2010.

Mätzler, C. and Schanda, E.: Snow mapping with active microwave sensors, Int. J. Remote Sens., 5, 409-422, 1984.

Mätzler, C. and Wiesmann, A.: Extension of the microwave emission model for layered snowpacks to coarse-grained snow, Remote Sens. Environ., 70, 318-326, 1999.

Mätzler, C.: Relation between grain-size and correlation length of snow, J. Glaciol., 48, 461-466, 2002.

Pan, J., Durand, M., Sandells, M., Lemmetyinen, J., Kim, E. J., Pulliainen, J., Kontu, A., and Derksen, C.: Differences between HUT snow emission model and MEMLS and their effects on brightness temperature simulation, IEEE Trans. Geosci. Remote Sens., 54, 2001-2019, 2016.

Proksch, M., Löwe, H., and Schneebeli, M.: Density, specific surface area, and correlation length of snow measured by highresolution penetrometry, J. Geophys. Res.-Earth, 120, 346-362, 2015a.

Proksch, M., Mätzler, C., Wiesmann, A., Lemmetyinen, J., Schwank, M., Löwe, H., and Schneebeli, M.: MEMLS3\&a: Microwave emission model of layered snowpacks adapted to 
include backscattering, Geosci. Model Dev., 8, 2611-2626, doi:10.5194/gmd-8-2611-2015, 2015 b.

Rautiainen, K., Lemmetyinen, J., Schwank, M., Kontu, A., Ménard, C., Mätzler, C., Drusch, M., Wiesmann, A., Ikonen, J., and Pulliainen, J.: Detection of soil freezing from L-band passive microwave observations. Remote Sens. Environ., 147, 206-218, 2014.

Rees, A., Lemmetyinen, J., Derksen, C., Pulliainen, J., and English, M.: Observed and modelled effects of ice lens formation on passive microwave brightness temperatures over snow covered tundra, Remote Sens. Environ., 114, 116-126, 2010.

Rott, H., Yueh, S., Cline, D., Duguay, C., Essery R., Haas, C., Heliere, F., Kern, M., Macelloni, G., Malnes, E., Nagler, T., Pulliainen, J., Rebhan, H., and Thompson, A.: Cold Regions Hydrology High-resolution Observatory for snow and cold land processes, Proc. IEEE, 98, 752-765, 2010.

Schneebeli, M. and Johnson, J.: A constant-speed penetrometer for high-resolution snow stratigraphy, Ann. Glaciol., 26, 107-111, 1998

Schwank, M., Wiesmann A., Werner, C., Mätzler, C., Weber, D., Murk A., Völksch, I., and Wegmüller, U.: ELBARA II, an Lband radiometer system for soil moisture research, Sensors, 10, 584-612, 2010.
Strozzi, T., Wiesmann, A., and Mätzler, C.: Active Microwave signatures of snow covers at 5.3 and $35 \mathrm{GHz}$, Radio Sci., 32, 479495, 1997.

Takala, M., Luojus, K., Pulliainen, J., Derksen, C., Lemmetyinen, J., Kärnä, J.-P., Koskinen, J., and Bojkov, B.: Estimating northern hemisphere snow water equivalent for climate research through assimilation of space-borne radiometer data and ground-based measurements, Remote Sens. Environ., 115, 3517-3529, 2011.

Tan, S., Chang, W., Tsang, L., Lemmetyinen, J., and Proksch, M.: Modeling both active and passive microwave remote sensing of snow using dense media radiative transfer (DMRT) theory with multiple scattering and backscattering enhancement, IEEE J. Select. T. App. Earth Obs. Remote Sens., 8, 4418-4430, 2015.

Werner, C., Wiesmann, A., Strozzi, T., Schneebeli, M., and Mätzler, C.: The SnowScat ground-based polarimetric scatterometer: Calibration and initial measurements from Davos Switzerland, in: Geoscience and Remote Sensing Symposium (IGARSS), 2010 IEEE International, 2363-2366, doi:10.1109/IGARSS.2010.5649015, 2010.

Wiesmann, A. and Mätzler, C.: Microwave emission model of layered snowpacks, Remote Sens. Environ., 70, 307-316, 1999. 